\title{
Phenols, Volatiles and Sensory Properties of Primitivo Wines from the "Gioia Del Colle" PDO Area
}

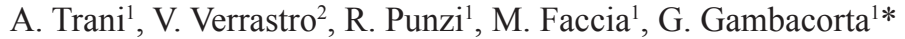

(1) Department of Soil, Plant and Food Science, University of Bari Aldo Moro, Via Amendola 165/A, I-70126, Bari, Italy

(2) CIHEAM-IAMB - International Centre for Advanced Mediterranean Agronomic Studies, Via Ceglie, 9, I-70010, Valenzano, Bari, Italy

Submitted for publication: March 2016

Accepted for publication: May 2016

Keywords: red wine, Primitivo, phenols, volatiles, sensory

\begin{abstract}
The aim of this study was to characterise the phenol, anthocyanin, volatile and sensory profiles of Primitivo wines. The wines were produced in three wineries located in the Gioia del Colle PDO (Protected Designation of Origin) area (Southern Italy - Apulia Region). The grapes came from three vineyards of different ages and were grown according to different training systems. The winemaking techniques applied also differed in some technological variables. The results obtained showed that all wines had a high alcohol content $(15$ to $16 \% \mathrm{v} / \mathrm{v})$ and were rich in total phenols and proanthocyanidins. The anthocyanin profile was characterised by the prevalence of non-acylated forms, of which malvidin-3- $O$-monoglucoside accounted for 62 to $67 \%$ of the total anthocyanin, followed by the coumarate, acetate and caffeate forms. The volatile fraction was constituted mainly alcohols and esters, the latter having concentrations above the odour threshold. From a sensory point of view, all wines were judged positively, and presented high olfactory and gustatory persistence. The main odour attributes found were soft fruits, cherry and cloves.
\end{abstract}

\section{INTRODUCTION}

Primitivo is one of the most important vines grown in Southern Italy, and particularly in the Apulia Region, where viticulture was introduced probably at the time of the Phoenician and Greek colonisation. The origin of the name Primitivo is probably related to its biological characteristics of an early flowering time and intermediate to early ripening. At the end of the $18^{\text {th }}$ century, the priest "primicerius", Francesco Filippo Indellicati from Gioia del Colle (Apulia, Italy), selected a lot of old and local vineyards with these characteristics in this area, resulting in the large utilisation of the Primitivo vine in this area. Later, around the end of the $19^{\text {th }}$ century, the vine also spread to the area of Taranto (Apulia, Italy). At present it is spread widely across two geographical areas with different Protected Designations of Origin (PDO): "Primitivo di Manduria" (provinces of Taranto and Brindisi) and "Gioia del Colle - Primitivo" (province of Bari). These two areas are very different in terms of soils - ranging from sandy to loamy - and climatic characteristics.

Primitivo grapes are used exclusively for winemaking, and the wines obtained commonly reach high alcohol levels and a ruby-purple colour (Antonacci, 2004). The vineyard training system has a large influence on the quality of grapes (sugars, acids, phenols and aroma compounds), whereas the winemaker affects the quality of the wine by choosing the appropriate winemaking technology. In red wines, the phenolic fraction is responsible for the sensory characteristics, such as colour, astringency and taste (Kosir et al., 2004; Ribéreau-Gayon et al., 2006), and for the biological properties, such as antioxidant and anti-inflammatory activities, and anti-atherosclerosis and cardio- and cancer-protective effects (Fresco et al., 2006; Soleas et al., 2006). As to the aromatic compounds, some volatile molecules are produced during fruit development and ripening. They represent the so-called "varietal aromas" or "primary aromas" that constitute the grape's signature. However, wine aroma depends on an extremely complex multi-mixture of numerous volatile substances belonging to different chemical species (Pisarnitskii, 2001; Polášková et al., 2008). The overall aroma is the results of the interactions between the sensory thresholds of these volatile substances and their concentration in the wine headspace. Besides the genetic expression, the biosynthesis of phenols and aroma compounds depends on climatic factors, including temperature, light and water availability (Ojeda et al., 2002; Castellarin et al., 2007; Sagratini et al., 2012). Thus, the pedo-climatic environment of grapevines and the growing area are of utmost importance to wine quality.

The literature contains only a few works on the quality

*Corresponding author: E-mail address: giuseppe.gambacorta@uniba.it [Tel: 0039 0805442942]

Acknowledgements: The authors gratefully acknowledge the Agricole Pietraventosa, Cantine Polvanera and Tenute Chiaromonte wineries, for their support of the work 
characteristics of Primitivo wines, in which only specific compounds (viz. phenols, volatiles) and features (antioxidant activity) have been investigated, but none refers to the "Gioia del Colle" area. Baiano et al. (2009) assessed the influence of nine winemaking technologies on the phenolic content and antioxidant activity of Primitivo musts and wines from the area of Manduria. They concluded that the addition of grapeseed tannins during maceration increases phenolic extraction and maintains the phenolic heritage, also during bottle ageing. Suriano et al. (2015) studied the influence of destemming of Primitivo grapes (100\%, 75\% and $50 \%$ ) from vineyards located in the territory of Sava on the proanthocyanin content in wines. They found that stem contact favoured condensation processes of anthocyaninsacetaldehyde-tannins, enhancing the colour intensity and stability of the wines. Stir bar sorptive extraction was used by Bononi et al. (2005) to study the effects of the production technology and wine ageing time on the volatile compounds of Primitivo wines from Manduria. Fragasso et al. (2012) evaluated the influence of training system on the volatile and sensory profiles of Primitivo grapes and wines from the area of Fragagnano. The aroma precursors, volatile compounds and sensory characteristics of the wine were improved when the grapes derived from little tree and bilateral Guyot training systems. Capone et al. (2013) determined the wine aroma volatiles of Negroamaro and Primitivo from Southern Apulia using SPE/GC-MS and electronic nose techniques. They found a correlation between volatile compounds and electronic nose responses using partial least squares and quadratic response surface regression analysis.

Recently, the market for Gioia del Colle - Primitivo PDO wine has been increasing worldwide, and it is important to deepen knowledge about its chemical and sensory traits as affected by environmental factors. The present study aimed to perform a preliminary characterisation of this wine by studying the phenolic and volatile fractions together with the sensory characteristics.

\section{MATERIALS AND METHODS \\ Sampling and winemaking}

The research was conducted in September 2013 on Primitivo wines from three wineries located in the PDO area "Gioia del Colle" in Apulia Region, Southern Italy: Agricole Pietraventosa (AP), Cantine Polvanera (CP) and Tenute Chiaromonte (TC). The grapes used in the winemaking derived from three vineyards permitted to produce the PDO wine, as indicated in the official protocol of production. The vineyards differed by place of growing, planting year, rootstock, training system and production yield, as reported in Table 1.

About 10 tons of grapes were harvested from each vineyard at so-called "technological maturity", corresponding to a total soluble solid content of 21 to $23^{\circ}$ Brix, and quickly transferred to the corresponding winery for industrial winemaking. The grapes were subjected to traditional red winemaking in stainless steel vats with pumping-over systems, following the protocols routinely used by the three wineries. The three winemaking protocols differed, as shown in Table 2. At the end of alcoholic fermentation and after static decantation, the wines were transferred to stainless steel tanks and stored in the cellar. For our study, about $50 \mathrm{~L}$ of wine was taken from each winery after six months, bottled without any post-treatment, and submitted to chemical and sensory analyses.

\section{Analysis of grapes Chemical analysis}

For each vineyard, a 300-berry sample was picked at vintage, cut leaving part of the peduncle intact, from the top, middle and bottom of the selected bunches to ensure a uniform and representative sample. A sub-sample of 150 berries ( 50 berries per replicate) was submitted to chemical analysis, whereas the remaining berries were used for the phenol analysis. As for the chemical analyses, berries were pressed and the juice was analysed for total soluble solids (TSS, ${ }^{\circ}$ Brix), $\mathrm{pH}$ and titratable acidity (TA, g/L tartaric acid) according to the EEC 2676 standard procedure (EEC, 1990).

\section{Phenol analysis}

The extraction of phenols from the grape skins was performed using 30 berries (three replicates for each sample) according to the method of Di Stefano and Cravero (2001) with some modifications. Briefly, the skins were removed manually from the pulp, gently dried with filter paper, and then macerated in $75 \mathrm{~mL}$ of ethanol/water/HCl solution $(70 / 30 / 1 \mathrm{v} / \mathrm{v})$ for $24 \mathrm{~h}$ in the dark at room temperature. The extract was then filtered through filter paper and immediately submitted to the analysis of the phenolic composition using an UV-visible spectrophotometer (Beckman Coulter DU 800, USA). Detailed procedures for the analysis of flavonoids (F), anthocyanins (A), total polyphenols (TP), proanthocyanidins (P) and flavans reactive with the vanillin (FRV) of grape skin extracts have been reported in a previous work (Gambacorta et al., 2011a).

\section{Analysis of wine \\ Chemical analysis}

The chemical characteristics of the wines were assessed by determining ethanol $(\mathrm{E}, \% \mathrm{v} / \mathrm{v}), \mathrm{pH}$, titratable acidity (TA, $\mathrm{g} / \mathrm{L}$ ), volatile acidity (VA, g/L acetic acid), malic acid (MA, $\mathrm{g} / \mathrm{L})$ and lactic acid (LA, g/L) using an AutoAnalyzer FOSS WineScan FT 120 FT-MIR spectrometer (FOSS, Padua, Italy).

\section{Phenol analysis}

The phenol composition (F, A, TP, FRV and P) was determined according to Di Stefano and Cravero (2001), whereas colour indices (CI, colour intensity; T, tonality) were assessed according to the Glories procedure (1984). The analysis of the anthocyanin profiles was performed by HPLC using a Waters 600 E apparatus (Waters, PA, USA) that included a quaternary pump, a photodiode array detector (DAD) and a Rheodyne injection valve with a $10 \mu \mathrm{L}$ loop. The samples, previously filtered on $0.22 \mu \mathrm{m}$ regenerated cellulose, were injected into a Nova-Pack C18 $(150 \times 3.9 \mathrm{~mm}, 4 \mu \mathrm{m}$ particle size, Waters) column maintained at $30^{\circ} \mathrm{C}$ and eluted at a flow rate of $1 \mathrm{~mL} / \mathrm{min}$ with $10 \%$ formic acid (solvent $\mathrm{A}$ ) and acetonitrile (solvent B). The gradient program of solvent $\mathrm{A}$ was as follows: 0 to $1 \mathrm{~min} 95 \%, 1$ to $22 \min 60 \%, 22$ to 23 $\min 30 \%, 23$ to $28 \min 30 \%, 28$ to $28.1 \min 95 \%$. Detection 
TABLE 1

Characteristics of vineyards.

\begin{tabular}{lllllll}
\hline Sample & Territory & District & Vineyard age & Training system & Rootstock & Yield (q/ha) \\
\hline AP & Gioia del Colle & Rosati & 2003 & Espalier & $140 \mathrm{Ru}$ & 75 \\
CP & Acquaviva delle Fonti & San Domenico & 1940 & Bush vine & $420 \mathrm{~A}$ & 40 \\
TC & Acquaviva delle Fonti & Barbatto & 1960 & Bush vine & $420 \mathrm{~A}$ & 50 \\
\hline
\end{tabular}

AP, Agricole Pietraventosa; CP, Cantine Polvanera; TC, Tenute Chiaromonte

TABLE 2

Winemaking technologies applied.

\begin{tabular}{|c|c|c|c|c|c|c|}
\hline \multirow[b]{2}{*}{ Sample } & \multicolumn{2}{|c|}{ Maceration } & \multirow[b]{2}{*}{$\begin{array}{l}\text { Pumping } \\
\text { over }(\mathrm{N})\end{array}$} & \multirow[b]{2}{*}{ Yeast } & \multirow[b]{2}{*}{ Yeast activator } & \multirow{2}{*}{$\begin{array}{l}\text { Potassium } \\
\text { metabisulphite } \\
(\mathrm{g} / 100 \mathrm{~kg})\end{array}$} \\
\hline & $\begin{array}{l}\text { Time } \\
\text { (days) }\end{array}$ & $\begin{array}{l}\text { Temperature } \\
\left({ }^{\circ} \mathrm{C}\right)\end{array}$ & & & & \\
\hline $\mathrm{AP}$ & 10 & $23-25$ & 2 & Mycoferm Rouge $^{\mathrm{A}}$ & $\begin{array}{l}\text { Vitamin B1, } \\
\text { ammonium sulphate }\end{array}$ & 10 \\
\hline $\mathrm{CP}$ & 10 & $24-26$ & 3 & Premium Zinfandel $^{\mathrm{B}}$ & $\begin{array}{l}\text { Vitamin B1, } \\
\text { ammonium sulphate }\end{array}$ & 7.5 \\
\hline TC & 15 & $20-22$ & 4 & Zymaflore F15 & None & 5 \\
\hline
\end{tabular}

AP, Agricole Pietraventosa; CP, Cantine Polvanera; TC, Tenute Chiaromonte

${ }^{\mathrm{A}}$ Ever Intec, Pramaggiore, Italy

${ }^{\mathrm{B} E n o l o g i c a}$ Vason, S. Pietro in Cariano, Italy

${ }^{\mathrm{C}}$ Laffort Oenologie Italy, Rho, Italy

was performed at $520 \mathrm{~nm}$, and quantitative analysis was done according to the external standard method on the basis of the calibration curve obtained by injecting solutions at different concentrations of malvidin-3-O-glucoside $\left(R^{2}=0.9991\right)$. Tentative identification of anthocyanin compounds was achieved by combining the elution pattern and data found by Revilla and Ryan (2000). The results were expressed as $\mathrm{mg} / \mathrm{L}$ of malvidin-3-O-glucoside equivalents.

\section{Antioxidant activity}

Antioxidant activity was assessed by ABTS [2,2'-azino-bis(3ethylbenzothiazoline-6-sulfonic acid)] assay, which is based on free radical-scavenging activity. Antioxidant activity was measured through the ability of antioxidants to scavenge the ABTS radical cation (ABTS ${ }^{++}$, a blue/green chromophore) by inhibiting its absorption at $734 \mathrm{~nm}$. The ABTS antioxidant test was performed according to the method reported by Re et al. (1999), with some modifications. To produce $\mathrm{ABTS}^{\cdot+}$, $7 \mathrm{mmol} / \mathrm{L}$ ABTS solution was reacted with $2.45 \mathrm{mmol} / \mathrm{L}$ potassium persulfate aqueous solution for $16 \mathrm{hrs}$ at room temperature and in the dark. The solution of $\mathrm{ABTS}^{\cdot+}$ was diluted with water to an absorbance of $0.80 \pm 0.1$ at $734 \mathrm{~nm}$. After the addition of $100 \mu \mathrm{L}$ of wine (diluted at 1:20 with water) to $3.9 \mathrm{~mL}$ of diluted $\mathrm{ABTS}^{\cdot+}$ solution, absorbance was measured after $5 \mathrm{~min}$. The results were expressed as $\mu \mathrm{mol} / \mathrm{L}$ TEAC (Trolox equivalent antioxidant capacity). Trolox standard solutions were prepared at a concentration ranging from 10 to $800 \mu \mathrm{mol} / \mathrm{L}$.

\section{Volatile analysis}

Volatile compounds were extracted by the HS-SPME technique using a preconditioned fibre, a $2 \mathrm{~cm}$ long 50/30 $\mu \mathrm{m}$ divinylbenzene/carboxen/polydimethylsiloxane
(DVB-CAR-PDMS) (Supelco, Bellefonte, Pa., USA). Two $\mathrm{mL}$ of wine, $5 \mathrm{~mL}$ of internal standard (2-heptanone) in hydro-alcoholic solution $(85 / 15, \mathrm{v} / \mathrm{v})$ at $10.25 \mathrm{mg} / \mathrm{L}$, and $0.4 \mathrm{~g}$ of $\mathrm{NaCl}$ were placed into a $12 \mathrm{~mL}$ screw-cap vial, tightly capped with a PTFE-silicon septum, and conditioned for $10 \mathrm{~min}$ at $37^{\circ} \mathrm{C}$ under stirring with a magnetic stirring bar (Summo et al., 2016). The fibre then was introduced into the headspace of the vial for $15 \mathrm{~min}$, removed and inserted into the GC injection port. Desorption of volatiles from the SPME fibre took place in a splitless mode at $220^{\circ} \mathrm{C}$ for $0.2 \mathrm{~min}$, and then the split valve was opened with a split ratio of 1:50. The fibre was kept in the injector port for 2 min as part of the cleaning process before introduction into another sample vial. The separation of volatile compounds was performed by an Agilent 6890 gas chromatograph (GC) coupled with an Agilent 5975 mass spectrometer (MS) (Agilent, Wilmington, Del., USA) using a HP Innowax column $(20 \mathrm{~m}$ length $\times 0.18 \mathrm{~mm}$ ID $\times 0.18 \mu \mathrm{m}$ film $)$. The chromatographic conditions were: (1) oven, $40^{\circ} \mathrm{C}(0.7 \mathrm{~min})$ to $180^{\circ} \mathrm{C}$ at $18^{\circ} \mathrm{C} / \mathrm{min}$, to $220^{\circ} \mathrm{C}$ at $20^{\circ} \mathrm{C} / \mathrm{min}$, held for 1 min; (2) detector, source temperature $250^{\circ} \mathrm{C}$; transfer line temperature $250^{\circ} \mathrm{C}$; (3) carrier gas, helium at constant flow of $0.7 \mathrm{~mL} / \mathrm{min}$. The impact energy was $70 \mathrm{eV}$. Data were acquired using the full-scan mode in the range of 34 to $200 \mathrm{~m} / \mathrm{z}$ at an acquisition rate of 7.2 Hz. Volatile compounds were tentatively identified by comparing the experimental spectra with those reported in the NIST Library and those obtained by injecting pure standard compounds, where available.

\section{Sensory analysis}

The panel of judges consisted of four oenology researchers from DiSSPA (Dipartimento di Scienze del Suolo, della 
Pianta e degli Alimenti), University of Bari (Italy) with more than 10 years of wine-tasting experience, and six professional tasters from the National Organization of Wine Tasters (ONAV, Italy). A profile sheet with nine descriptors and a sheet with a list of odorous attributes developed in a previous study were used (Coletta et al., 2013). The judges were asked to assign a score for different parameters of the wines, such as colour intensity, olfactory intensity and persistence, gustatory intensity and persistence, acidity, astringency, body and overall judgment, using a sensorial analysis tasting sheet with a scale ranging from 0 (absence of perception) to 10 (maximum perception). The mean scores of attributes were submitted to quantitative descriptive analysis (QDA) in order to generate the sensory profile of the wines. Moreover, the judges were asked to report the perception of odorous attributes in the sample. The most significant of the odorous attributes perceived were chosen, and their frequency was reported in a graph.

\section{Statistical analysis}

Chemical analyses were repeated three times for each sample. One-way ANOVA was performed by means of SPSS software v. 19 (IBM Corporation, NY, USA) in order to evaluate the differences among samples for the mean values of chemical, phenolic and sensorial characteristics.

\section{RESULTS AND DISCUSSION}

\section{Chemical and phenolic characteristics of grapes}

Table 3 shows the technological ripening indices and the phenolic composition of the grapes at harvest. All grapes had high values of TSS (21.41 to $\left.22.65^{\circ} \mathrm{Brix}\right)$ and TA (6.09 to $6.46 \mathrm{~g} / \mathrm{L})$, and a low $\mathrm{pH}$ (3.24 to 3.38), showing an optimal ripening status. The $\mathrm{CP}$ sample showed the highest value of TSS, followed by AP and TC; the latter was characterised by the best acidic structure (lowest $\mathrm{pH}$ and highest TA). Concerning phenolic characteristics, CP showed the highest content of A and FRV, whereas AP had the highest TP and P levels. The differences found could be due to the different training systems, plant age and the location of the vineyards.

\section{Chemical and phenolic composition of wines}

The chemical and phenolic composition and the colour indices the of wines are reported in Table 4. All samples showed a high ethanol content, especially CP (16\% v/v). The values were higher than expected considering the TSS content of the grapes, and this could be explained by the presence of dried berries in the clusters of grapes at harvest.
Dried berries are poor in juice but very rich in sugars, and this could have resulted in an underestimation of the TSS content at grape sampling and, as a consequence, in the high ethanol content of the wine. The alcohol content was about $30 \%$ higher than Primitivo wines from Manduria (Baiano et al., 2009) and about 30\% lower than Primitivo wines from Sava (Suriano et al., 2015). TC had a higher $\mathrm{pH}$ and lower titratable acidity than the AP and CP samples. This is in disagreement with the characteristics of the grapes used in winemaking (Table 3). The lower acidic structure found in TC could be explained by the prolonged maceration ( 15 days) and by the greater number of pumping overs (four) during winemaking, which could have led to the strong extraction of potassium, inducing tartaric precipitation (Gambacorta et al., 2011b). Malolactic fermentation did not start in CP, had only just begun in TC, and was almost completed in AP. All samples showed a low value of VA, pointing to the high quality of the raw material and the correct management of winemaking.

The phenolic content and composition of a young red wine commonly depend on the phenolic concentration of the grapes used and, mainly, on the technology applied (Baiano et al., 2009). In contrast, the wine samples in the present study showed different phenolic compositions in comparison with the corresponding grapes used in winemaking. For instance, the AP wine had the lowest content of P, even though these compounds were highly present in the grapes. This could be explained by the winemaking technology applied, which included a short maceration time coupled with a low number of pumping-over operations per day. Furthermore, TC was richer in A than $\mathrm{CP}$ and $\mathrm{AP}$, despite the grapes used in winemaking being the poorest in A. This could be explained by the prolonged maceration applied during the winemaking (15 days versus 10 days), coupled with more pumping overs that increased the extraction and the lowest temperature of maceration, which preserved the anthocyanins from oxidation. Our results are in agreement with those of Romero-Cascales et al. (2005), who demonstrated that the anthocyanin content of wine is not always correlated with the anthocyanin concentration of the grapes used in winemaking. FRV in all wines was found to be less than onethird of P: this parameter is an index of the concentration of astringent tannins, and the sum of FRV and P constitutes the total tannin content of the wine. This information is important, as it provides an objective measurement of the sensation of astringency that is provided by the wine during tasting. When the total tannins/astringent tannins ratio is

TABLE 3

Chemical and phenolic characteristics of Primitivo grapes at harvest (mean values $\pm \mathrm{SD}$ ).

\begin{tabular}{lllllllll}
\hline Samples & TSS ( ${ }^{\circ}$ Brix $)$ & $\mathrm{pH}$ & $\mathrm{TA}(\mathrm{g} / \mathrm{L})$ & $\mathrm{F}(\mathrm{mg} / \mathrm{kg})$ & $\mathrm{A}(\mathrm{mg} / \mathrm{kg})$ & $\mathrm{TP}(\mathrm{mg} / \mathrm{kg})$ & $\mathrm{FRV}(\mathrm{mg} / \mathrm{kg})$ & $\mathrm{P}(\mathrm{mg} / \mathrm{kg})$ \\
\hline AP & $121.60 \pm 0.07^{\mathrm{b}}$ & $3.28 \pm 0.04^{\mathrm{b}}$ & $6.09 \pm 0.04^{\mathrm{b}}$ & $2333 \pm 125^{\mathrm{b}}$ & $1479 \pm 90^{\mathrm{b}}$ & $2172 \pm 132^{\mathrm{a}}$ & $562 \pm 30^{\mathrm{b}}$ & $2799 \pm 118^{\mathrm{a}}$ \\
$\mathrm{CP}$ & $22.65 \pm 0.07^{\mathrm{a}}$ & $3.38 \pm 0.02^{\mathrm{a}}$ & $6.36 \pm 0.08^{\mathrm{a}}$ & $2391 \pm 117^{\mathrm{b}}$ & $1771 \pm 90^{\mathrm{a}}$ & $1938 \pm 5^{\mathrm{b}}$ & $603 \pm 38^{\mathrm{a}}$ & $2465 \pm 105^{\mathrm{b}}$ \\
TC & $21.41 \pm 0.14^{\mathrm{b}}$ & $3.24 \pm 0.01^{\mathrm{b}}$ & $6.46 \pm 0.06^{\mathrm{a}}$ & $2588 \pm 79^{\mathrm{a}}$ & $1432 \pm 73^{\mathrm{b}}$ & $1929 \pm 13^{\mathrm{b}}$ & $595 \pm 51^{\mathrm{a}}$ & $2556 \pm 97^{\mathrm{b}}$ \\
\hline
\end{tabular}

AP, Agricole Pietraventosa; CP, Cantine Polvanera; TC, Tenute Chiaromonte

TSS, total soluble solid; TA, titratable acidity: as tartaric acid; F, flavonoids: as (+)-catechin; A, anthocyanins: as malvidin-3-glucoside; TP, total polyphenols: as gallic acid; FRV, flavans reactive with vanillin: as $(+)$-catechin; $P$, proanthocyanidins: as cyanidin chloride

'In columns, data followed by different letters indicate statistically significant differences at $P<0.05$ 
greater than 2 , the latter compounds are not predominant and the wine is slightly astringent. In our wines, the value ranged from 4 to 5 , therefore they were not expected to be very astringent. In comparison with the phenol composition of Primitivo wines from other areas (Baiano et al., 2009; Coletta et al., 2013; Suriano et al., 2015), our Primitivo wines had a proanthocyanidin content of about $50 \%$ higher and the same amount of FRV. Therefore, the total tannins/ astringent tannins ratio of our wines was higher (4 to 5 versus 2.6 to 2.7) and, consequently, Gioia del Colle wines should be less astringent. All the wines showed high values of AA: CP was the richest sample, followed by AP and TC. This finding matches the polyphenol content, as expected, since the two parameters are strictly correlated (FernándezPachón et al., 2004; Li et al., 2009). Concerning colour indices, the $\mathrm{CP}$ wine showed the highest value of $\mathrm{CI}$, and consequently the lowest value of T, followed by AP and TC. The colour indices are not only linked to the anthocyanin content, but also to the acidic structure, mainly to $\mathrm{pH}$. In fact, anthocyanins in an acid medium are red, losing their colour as $\mathrm{pH}$ increases (Ribéreau-Gayon et al., 2006). The lowest CI value in the TC sample was due to the longest maceration time, since it is well known that colour intensity decreases after about eight to 10 days.

\section{Anthocyanin profile of wines}

The average content of anthocyanin compounds is reported in Table 5. The extractability of anthocyanins from grapes during maceration depends on the variety, geographical origin, vintage and winemaking techniques (Ortega-Regules et al., 2008). Fourteen monomeric anthocyanins were identified, including five non-acylated forms and nine acylated forms, and they were different from a quantitative point of view. TC showed a total anthocyanin content about fourfold higher than that of AP and CP. This could be due to the low maceration temperature applied, which limited anthocyanin oxidation and reactions with various compounds, especially tannins. As to the anthocyanin composition, non-acylated forms were the most abundant, ranging from about $78 \%$ for $\mathrm{CP}$ to about $83 \%$ for AP and TC. Malvidin-3-O-glucoside $(\mathrm{Mv})$, which is responsible for the blue-red colour of wines, was the most abundant component, accounting for 62 to $67 \%$ of the total anthocyanin content, in agreement with that observed by Baiano et al. (2009) and Suriano et al. (2015). Petunidin-3-O-glucoside (Pt) was the second most abundant compound, accounting for 6 to $9 \%$, while cyanidin-3-Oglucoside (Cy) was the least abundant, accounting for 0.5 to $3 \%$. Among the acylated forms, accounting for 17 to $22 \%$ of the total anthocyanin content, coumarates were the most abundant (13\%), followed by acetate ( 1 to $5 \%$ ) and caffeate $(0.5$ to $1.5 \%)$. The ratio of acetate to coumarate anthocyanins has been proposed to be used to evaluate the authenticity of specific varieties of wines (Burns et al., 2002; Otteneder et al., 2008).

\section{Volatile profile of wines}

In Table 6, the volatile compounds of the wines grouped according to the chemical class (alcohols, esters, acids, aldehydes and other) are reported. The odour threshold and odour description are also indicated for each compound. The ratio between the concentration of a volatile compound and its odour threshold is called "aroma value". When a volatile compound has an aroma value greater than 1 it could be involved in aroma perception. Although this concept is subject to criticism, it remains a useful tool to reveal active aroma compounds that are responsible for flavours and off-flavours in food. The SPME/GC-MS analysis allowed the identification of a total of 31 volatile compounds in

TABLE 4

Chemical characteristics, phenolic composition and colour indices of Primitivo wines (mean values \pm SD).

\begin{tabular}{|c|c|c|c|}
\hline Parameters & AP & $\mathrm{CP}$ & $\mathrm{TC}$ \\
\hline $\mathrm{E}(\% \mathrm{v} / \mathrm{v})$ & $\dagger 15.22 \pm 0.01^{b}$ & $16.00 \pm 0.02^{\mathrm{a}}$ & $14.86 \pm 0.01^{\mathrm{c}}$ \\
\hline $\mathrm{pH}$ & $3.36 \pm 0.03^{\mathrm{a}}$ & $3.26 \pm 0.03^{b}$ & $3.39 \pm 0.04^{\mathrm{a}}$ \\
\hline $\mathrm{TA}(\mathrm{g} / \mathrm{L})$ & $6.70 \pm 0.06^{\mathrm{b}}$ & $7.00 \pm 0.07^{\mathrm{a}}$ & $6.50 \pm 0.06^{\mathrm{c}}$ \\
\hline $\mathrm{VA}(\mathrm{g} / \mathrm{L})$ & $0.41 \pm 0.04^{\mathrm{a}}$ & $0.44 \pm 0.04^{\mathrm{a}}$ & $0.21 \pm 0.02^{\mathrm{b}}$ \\
\hline $\mathrm{MA}(\mathrm{g} / \mathrm{L})$ & $0.50 \pm 0.01^{\mathrm{c}}$ & $1.40 \pm 0.01^{\mathrm{b}}$ & $1.50 \pm 0.01^{\mathrm{a}}$ \\
\hline $\mathrm{LA}(\mathrm{g} / \mathrm{L})$ & $1.20 \pm 0.01^{\mathrm{a}}$ & nd & $0.10 \pm 0.00^{\mathrm{b}}$ \\
\hline $\mathrm{F}(\mathrm{mg} / \mathrm{L})$ & $1984 \pm 72^{c}$ & $2503 \pm 33^{a}$ & $2263 \pm 90^{b}$ \\
\hline $\mathrm{A}(\mathrm{mg} / \mathrm{L})$ & $302 \pm 18^{c}$ & $401 \pm 15^{b}$ & $519 \pm 31^{\mathrm{a}}$ \\
\hline $\mathrm{TP}(\mathrm{mg} / \mathrm{L})$ & $3064 \pm 81^{\mathrm{b}}$ & $3794 \pm 127^{a}$ & $2962 \pm 49^{b}$ \\
\hline $\mathrm{FRV}(\mathrm{mg} / \mathrm{L})$ & $1086 \pm 74^{\mathrm{a}}$ & $1091 \pm 63^{\mathrm{a}}$ & $906 \pm 88^{b}$ \\
\hline $\mathrm{P}(\mathrm{mg} / \mathrm{L})$ & $3282 \pm 105^{c}$ & $3853 \pm 126^{\mathrm{a}}$ & $3629 \pm 89^{b}$ \\
\hline $\mathrm{AA}(\mathrm{mg} / \mathrm{L})$ & $14147 \pm 422^{b}$ & $14960 \pm 460^{\mathrm{a}}$ & $14010 \pm 434^{b}$ \\
\hline CI (path length $1 \mathrm{~mm}$ ) & $1.31 \pm 0.09^{\mathrm{b}}$ & $1.99 \pm 0.02^{\mathrm{a}}$ & $0.90 \pm 0.04^{\mathrm{c}}$ \\
\hline T (path length $1 \mathrm{~mm}$ ) & $0.70 \pm 0.02^{\mathrm{a}}$ & $0.58 \pm 0.01^{\mathrm{c}}$ & $0.63 \pm 0.01^{\mathrm{b}}$ \\
\hline
\end{tabular}

AP, Agricole Pietraventosa; CP, Cantine Polvanera; TC, Tenute Chiaromonte. E, ethanol; TA, titratable acidity: as tartaric acid; VA, volatile acidity: as acetic acid; MA, malic acid; LA, lactic acid; F, flavonoids: as (+)-catechin; A, anthocyanins: as malvidin-3-glucoside; TP, total polyphenols: as gallic acid; FRV, flavans reactive with vanillin: as (+)-catechin; P, proantocyanidins: as cyanidin chloride; CI, colour intensity; $\mathrm{T}$, tonality. 'In rows, data followed by different letters indicate statistically significant differences at $P<0.05$. nd, not detected 
TABLE 5

Anthocyanin composition of Primitivo wines (mg/L, mean values $\pm \mathrm{SD}$ ).

\begin{tabular}{llll}
\hline Compounds & AP & CP & TC \\
\hline Dp & $\dagger 1.18 \pm 0.01^{\mathrm{b}}$ & $1.24 \pm 0.20^{\mathrm{b}}$ & $3.47 \pm 0.21^{\mathrm{a}}$ \\
$\mathrm{Cy}$ & $1.08 \pm 0.02^{\mathrm{a}}$ & $0.72 \pm 0.02^{\mathrm{b}}$ & $0.66 \pm 0.05^{\mathrm{b}}$ \\
$\mathrm{Pt}$ & $2.23 \pm 0.24^{\mathrm{c}}$ & $2.71 \pm 0.08^{\mathrm{b}}$ & $11.40 \pm 0.13^{\mathrm{a}}$ \\
Pn & $1.60 \pm 0.16^{\mathrm{b}}$ & $1.88 \pm 0.18^{\mathrm{b}}$ & $6.39 \pm 0.23^{\mathrm{a}}$ \\
$\mathrm{Mv}$ & $22.55 \pm 1.14^{\mathrm{b}}$ & $25.28 \pm 0.78^{\mathrm{c}}$ & $86.11 \pm 1.3^{\mathrm{a}}$ \\
Dp-Ac & $0.16 \pm 0.04^{\mathrm{b}}$ & $0.52 \pm 0.06^{\mathrm{a}}$ & $0.17 \pm 0.07^{\mathrm{b}}$ \\
Pt-Ac & $0.52 \pm 0.05^{\mathrm{c}}$ & $1.17 \pm 0.01^{\mathrm{a}}$ & $0.78 \pm 0.05^{\mathrm{b}}$ \\
Mv-Ac & $0.08 \pm 0.03^{\mathrm{c}}$ & $0.42 \pm 0.06^{\mathrm{b}}$ & $0.74 \pm 0.09^{\mathrm{a}}$ \\
Dp-Cm & $2.49 \pm 0.01^{\mathrm{b}}$ & $2.53 \pm 0.08^{\mathrm{c}}$ & $4.53 \pm 0.15^{\mathrm{a}}$ \\
cis-Mv-Cm & $0.07 \pm 0.02^{\mathrm{a}}$ & $0.10 \pm 0.05^{\mathrm{a}}$ & $0.09 \pm 0.01^{\mathrm{a}}$ \\
Mv-Cf & $0.18 \pm 0.04^{\mathrm{c}}$ & $0.56 \pm 0.06^{\mathrm{b}}$ & $0.77 \pm 0.03^{\mathrm{a}}$ \\
Pt-Cm & $0.41 \pm 0.04^{\mathrm{c}}$ & $0.96 \pm 0.07^{\mathrm{b}}$ & $1.20 \pm 0.04^{\mathrm{a}}$ \\
Pn-Cm & $0.38 \pm 0.05^{\mathrm{b}}$ & $0.29 \pm 0.01^{\mathrm{c}}$ & $1.80 \pm 0.00^{\mathrm{a}}$ \\
trans-Mv-Cm & $1.38 \pm 0.11^{\mathrm{b}}$ & $40.59 \pm 0.04^{\mathrm{b}}$ & $9.17 \pm 0.07^{\mathrm{a}}$ \\
Total anthocyanins & $34.95 \pm 2.07^{\mathrm{c}}$ & $128.99 \pm 3.49^{\mathrm{a}}$ \\
\hline APA & & & \\
\hline
\end{tabular}

AP, Agricole Pietraventosa; CP, Cantine Polvanera; TC, Tenute Chiaromonte

Dp, delphinidin-3-O-glucoside; Cy, cyanidin-3-O-glucoside; Pt, petunidin-3-O-glucoside; $\mathrm{Pn}$, peonidin-3-O-glucoside; $\mathrm{Mv}$, malvidin-3-Oglucoside; Dp-Ac, delphinidin-3-O-acetylglucoside; Pt-Ac, petunidin-3-O-acetylglucoside; Mv-Ac, malvidin-3-O-acetylglucoside; Dp-Cm, delphinidin-3-O-coumarylglucoside; cis-Mv-Cm, cis-malvidin-3-O-coumarylglucoside; Mv-Cf, malvidin-3-O-caffeylglucoside; Pt-Cm, petunidin-3-O-coumarylglucoside; $\mathrm{Pn}-\mathrm{Cm}$, peonidin-3-O-coumarylglucoside; trans-Mv-Cm, trans-malvidin-3-O-coumarylglucoside 'In rows, data followed by different letters indicate statistically significant differences at $P<0.05$.

the samples, of which 27 were present in AP, 22 in TC and 16 in CP. It is noteworthy that the highest number of compounds was found in the AP wine, in which malolactic fermentation was almost complete. In addition, AP presented a greater total concentration of volatiles than $\mathrm{CP}$ and $\mathrm{TC}$. The volatile content of Primitivo Gioia del Colle DOC wines found in our study was about one tenth of that found by Capone et al. (2013) in Primitivo wines from other areas of Apulia, but it must be pinpointed that they used the SPE/ GC-MS technique, which is more sensitive. However, from a quantitative point of view, our results are in good accordance with those reported in the literature when the extraction of volatiles was carried out by SPME/GC-MS (Canuti et al., 2009). In our opinion, the SPME technique as extraction method from the headspace is more comparable with the assessment of odorous compounds by the human nose during sniffing. Among the volatile compounds, the alcohols were the most abundant in all samples, constituting about 64,50 and $66 \%$ of the total for AP, CP and TC respectively. The second most abundant group was that of esters, which accounted for about 33,49 and $30 \%$ of the total for AP, CP and $\mathrm{TC}$ respectively. The other groups were detected at very low levels $(<3.3 \%$ of the total). Alcohols are synthesised by yeast during fermentation and are released into the wine as by-products of their metabolism, or by catabolism of the corresponding amino acids. It is well known that their level in wine is a function of the composition of the grapes, the yeast strain, the temperature of fermentation, the availability of oxygen and any material in suspension. Alcohols are recognisable by their strong and pungent smell and taste (Etiévant, 1991; Baumes, 2000; Kotseridis
\& Baumes, 2000; Gil Diaz et al., 2005). Isoamyl alcohol (1-butanol, 3-methyl) was the most abundant compound in all the wines, ranging from $8.25 \mathrm{mg} / \mathrm{L}(\mathrm{CP})$ to $13.54 \mathrm{mg} / \mathrm{L}$ (AP). Even though this molecule is responsible for alcohol and fusel notes, the concentrations found were below the odour threshold $(30 \mathrm{mg} / \mathrm{L})$ and it did not contribute to wine aroma. Phenylethyl alcohol, responsible for honey, spice, rose and lilac notes, was the second major alcoholic compound. The amounts detected in the AP and TC samples were greater than the odour threshold $(0.75 \mathrm{mg} / \mathrm{L})$ and, consequently, this compound can be involved in wine aroma. 2-Methyl-1-propanol and 1-hexanol were the two other alcohols detected in all wines, but at lower concentrations than their odour thresholds (40 and $8 \mathrm{mg} / \mathrm{L}$ respectively). In comparison with the $\mathrm{CP}$ and $\mathrm{TC}$ samples, $\mathrm{AP}$ wine was characterised by the presence of three other alcohols (3-methyl-1-pentanol, 2-ethyl-1-hexanol and 1-octanol) as minor compounds, at lower concentrations $(<0.05 \mathrm{mg} / \mathrm{L})$ than the odour thresholds. Esters were the largest group in terms of the number of identified compounds (16), of which the majority were found at concentration above the odour threshold. Ethyl esters of fatty acids and acetates have long been considered important contributors to wine aroma (Etiévant, 1991). Ethyl esters are synthesised mainly during yeast fermentation; it is well known that their concentrations are influenced by the yeast strain, fermentation temperature, degree of aeration and sugar content. Acetates are the result of reactions involving acetylCoA and alcohols deriving from the degradation of amino acids or carbohydrates. Both esters and acetates have a key role in the whole wine aroma, making a positive contribution by distinct sensory 
TABLE 6

Mean concentration of free volatile compounds $(\mathrm{mg} / \mathrm{L})$ and relative standard deviation $(\mathrm{n}=3)$ of Primitivo wines.

\begin{tabular}{|c|c|c|c|c|c|c|c|}
\hline \multirow[b]{2}{*}{ Compounds } & \multicolumn{2}{|c|}{ LRI } & \multirow[b]{2}{*}{ AP } & \multirow[b]{2}{*}{$\mathrm{CP}$} & \multirow[b]{2}{*}{$\mathrm{TC}$} & \multirow{2}{*}{$\begin{array}{l}\text { Odour } \\
\text { threshold } \\
(\mathrm{mg} / \mathrm{L})\end{array}$} & \multirow[b]{2}{*}{ Odour description } \\
\hline & Exp. ${ }^{\dagger}$ & Lit. ${ }^{*}$ & & & & & \\
\hline 1-Propanol, 2-methyl & 1098 & 1097 & $0.63 \pm 0.18$ & $0.81 \pm 0.11$ & $0.73 \pm 0.43$ & $40[1]$ & Wine, solvent, bitter \\
\hline 1-Butanol, 3-methyl & 1217 & 1215 & $\S 13.54 \pm 0.18^{\mathrm{a}}$ & $8.25 \pm 0.46^{\mathrm{c}}$ & $11.06 \pm 1.61^{\mathrm{b}}$ & $30[1]$ & Whiskey, malt, burnt \\
\hline 1-Pentanol, 3-methyl- & 1332 & 1325 & $0.03 \pm 0.01$ & nd & nd & $1[2]$ & Herb, cacao \\
\hline 1-Hexanol & 1361 & 1354 & $0.39 \pm 0.07^{\mathrm{a}}$ & $0.22 \pm 0.08^{b}$ & $0.24 \pm 0.09^{\mathrm{ab}}$ & $8[3]$ & Resin, flower, green \\
\hline 1-Heptanol & 1467 & 1460 & nd & nd & $0.07 \pm 0.02$ & $0.003[4]$ & Herb \\
\hline 1-Hexanol, 2-ethyl- & 1503 & 1492 & $0.04 \pm 0.01$ & nd & nd & $270[4]$ & Rose, green \\
\hline 1-Octanol & 1569 & 1561 & $0.04 \pm 0.01$ & nd & nd & $0.11[4]$ & Nut, chemical, burnt \\
\hline Phenylethyl alcohol & 1927 & $1925^{*}$ & $1.86 \pm 0.22^{\mathrm{a}}$ & $0.48 \pm 0.06^{b}$ & $2.21 \pm 0.40^{\mathrm{a}}$ & $0.75[5]$ & Honey, spice, rose, lilac \\
\hline Total alcohols & & & $16.53 \pm 0.68^{a}$ & $9.76 \pm .41^{c}$ & $14.31 \pm 0.65^{b}$ & & \\
\hline Ethyl acetate & 895 & 893 & $3.84 \pm 0.24^{\mathrm{b}}$ & $7.34 \pm 0.10^{\mathrm{a}}$ & $2.36 \pm 0.97^{\mathrm{c}}$ & $12.3[1]$ & Pineapple \\
\hline Ethyl isobutyrate & 965 & 960 & $0.11 \pm 0.02^{b}$ & $0.18 \pm 0.04^{\mathrm{a}}$ & nd & $0.015[3]$ & Fruit, apple \\
\hline Isobutyl acetate & 1009 & 1018 & $0.03 \pm 0.01$ & nd & nd & $0.066[4]$ & Fruit, apple, banana \\
\hline Ethyl isovalerate & 1028 & 1024 & $0.12 \pm 0.04^{\mathrm{a}}$ & $0.07 \pm 0.01^{b}$ & $0.07 \pm 0.02^{b}$ & $0.003[3]$ & Fruit, lemon, anise \\
\hline Ethyl butyrate & 1034 & 1040 & $0.19 \pm 0.03^{\mathrm{a}}$ & $0.14 \pm 0.01^{\mathrm{b}}$ & $0.13 \pm 0.02^{b}$ & $0.002[3]$ & Apple \\
\hline Isoamyl acetate & 1132 & 1125 & $0.59 \pm 0.14^{\mathrm{ab}}$ & $0.40 \pm 0.16^{\mathrm{b}}$ & $0.84 \pm 0.16^{\mathrm{a}}$ & $0.03[1]$ & Banana \\
\hline Ethyl 2-methylbutyrate & 1145 & 1138 & $0.06 \pm 0.01$ & nd & $0.04 \pm 0.02$ & $0.018[3]$ & Fruit, anise \\
\hline Ethyl hexanoate & 1242 & 1238 & $1.84 \pm 0.49^{\mathrm{a}}$ & $0.84 \pm 0.39^{b}$ & $0.85 \pm 0.02^{b}$ & $0.014[3]$ & Apple peel, fruit \\
\hline Hexyl acetate & 1274 & 1269 & $0.01 \pm 0.01$ & nd & nd & $0.002[4]$ & Fruit, herb \\
\hline Ethyl heptanoate & 1340 & 1331 & $0.04 \pm 0.02$ & $0.07 \pm 0.03$ & $0.05 \pm 0.03$ & $\begin{array}{l}0.0022 \\
{[6]}\end{array}$ & Fruit \\
\hline Methyl octanoate & 1395 & 1387 & $0.02 \pm 0.01$ & nd & nd & $0.2[6]$ & Orange \\
\hline Ethyl octanoate & 1442 & 1438 & $1.62 \pm 0.47$ & $1.01 \pm 0.38$ & $1.72 \pm 0.36$ & $0.005[3]$ & Fruit, fat \\
\hline Ethyl decanoate & 1653 & 1647 & $0.11 \pm 0.04^{\mathrm{b}}$ & $0.11 \pm 0.02^{\mathrm{b}}$ & $0.21 \pm 0.05^{\mathrm{a}}$ & $0.2[3]$ & Grape \\
\hline Total esters & & & $8.58 \pm 0.57^{b}$ & $10.16 \pm 0.68^{a}$ & $6.27 \pm 0.48^{c}$ & & \\
\hline Acetic acid & 1483 & 1480 & $0.45 \pm 0.08^{\mathrm{a}}$ & $0.68 \pm 0.16^{\mathrm{a}}$ & $0.18 \pm 0.02^{\mathrm{b}}$ & $20-175$ & Sour, pungent, vinegar \\
\hline Isobutyric acid & 1573 & $1563 *$ & nd & nd & $0.04 \pm 0.01$ & $0.23[3]$ & Rancid, butter, cheese \\
\hline Hexanoic acid & 1855 & 1847 & $0.05 \pm 0.02$ & nd & $0.03 \pm 0.01$ & $0.42[3]$ & Sweat \\
\hline Octanoic acid & 2092 & $2083 *$ & $0.06 \pm 0.03$ & nd & $0.04 \pm 0.01$ & $0.5[3]$ & Sweat, cheese \\
\hline Total acids & & & $0.56 \pm 0.13^{a}$ & $0.68 \pm 0.16^{a}$ & $0.29 \pm 0.05^{b}$ & & \\
\hline Nonanal & 1402 & 1396 & $0.01 \pm 0.01$ & nd & nd & $0.001[5]$ & Fat, citrus, green \\
\hline Furfural & 1482 & 1474 & $0.05 \pm 0.01^{\mathrm{b}}$ & $0.10 \pm 0.03^{\mathrm{a}}$ & $0.07 \pm 0.01^{\mathrm{ab}}$ & $14[3]$ & Bread, almond, sweet \\
\hline Total aldehydes & & & $0.06 \pm 0.02$ & $0.10 \pm 0.03$ & $0.07 \pm 0.01$ & & \\
\hline 2-n-Butyl furan & 1248 & 1240 & nd & $0.09 \pm 0.02$ & nd & $10[7]$ & Mild fruit, wine, sweet \\
\hline Butyrolactone & 1658 & 1647 & $0.03 \pm 0.01$ & nd & $0.02 \pm 0.01$ & $20[8]$ & Caramel, sweet, buttery \\
\hline Total lactones & & & $0.03 \pm 0.01^{b}$ & $0.09 \pm 0.02^{a}$ & $0.02 \pm 0.01^{b}$ & & \\
\hline$\alpha$-Terpineol & 1692 & 1688 & nd & nd & $0.01 \pm 0.01$ & $0.25[3]$ & Flower \\
\hline Methionol & 1727 & 1723 & $0.01 \pm 0.01$ & nd & $0.02 \pm 0.01$ & $1[1]$ & Sweet, potato \\
\hline Total other & & & $0.01 \pm 0.01$ & & $0.03 \pm 0.01$ & & \\
\hline Total contents & & & $25.77 \pm 1.38^{\mathrm{a}}$ & $20.79 \pm 1.06^{b}$ & $20.99 \pm 1.28^{b}$ & & \\
\hline
\end{tabular}

AP, Agricole Pietraventosa; CP, Cantine Polvanera; TC, Tenute Chiaromonte

LRI, linear retention index

'LRI on HP-Innovax column, experimentally determined using homologous series of $\mathrm{C}_{8}-\mathrm{C}_{30}$ alkanes

${ }^{*}$ LRI taken from Bianchi et al. [2007]

*LRI taken from www.flavornet.org

[1] Guth, 1997; [2] Zea et al., 2001; [3] Ferreira et al., 2000; [4] Fazzalari, 1978; [5] Buttery et al., 1988; [6] Takeoka et al., 1990; [7] Evans et al., 1971; [8] Silva Ferreira, 1998

${ }^{\S}$ In rows, data followed by different letters indicate statistically significant differences at $P<0.05$. nd: not detected. 
A

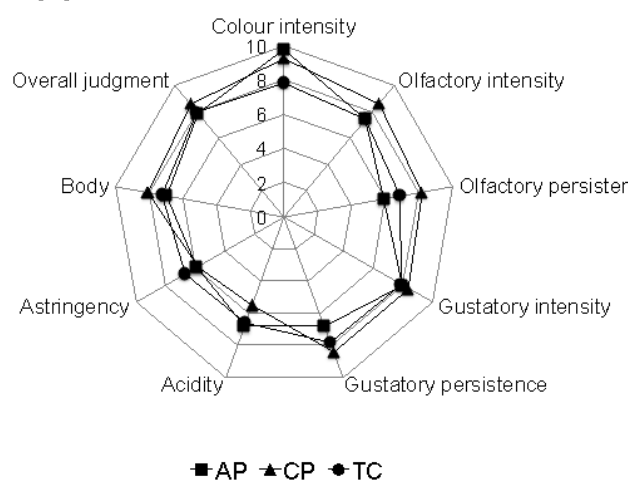

B

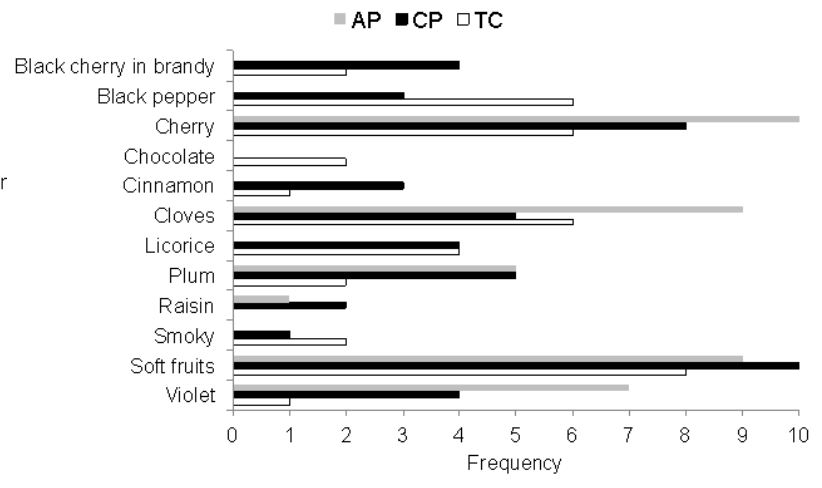

FIGURE 1

Sensory profile (A) and frequency of the aromatic descriptors (B) of wines. AP, Agricole Pietraventosa; CP, Cantine Polvanera; TC, Tenute Chiaromonte

notes: sweet-fruity, grape-like odour, sweet-balsamic (Rapp, 1990; Swiegers \& Pretorius, 2005). Ethyl octanoate and ethyl hexanoate showed the highest aroma value, followed by ethyl isovalerate, ethyl heptanoate and isoamyl acetate. These esters are generally described as fruit and apple. Acids constitute a group of aroma compounds that could contribute negatively to aroma, with odorous notes such as cheese, fatty and rancid (Rocha et al., 2004). Four acids were identified in our samples, of which acetic acid was predominant, but at concentrations much below the odour threshold. Other volatile compounds were also identified, but they were less numerous and at very low levels.

\section{Sensory profile of wines}

Sensory analysis was performed involving the senses of sight, smell and taste, and the results were subjected to QDA (Fig. 1A). The assessment of the selected aroma descriptors was performed via smell and expressed as a frequency of the judge's citation (Fig. 1B). All wines obtained good overall judgment and, even though the samples were produced using grapes from vineyards of different ages and by different technologies, the overall scores were only slightly different. Higher colour intensity was perceived for AP and CP, in accordance with the spectrophotometric analysis (Table 4). AP exhibited less olfactory and gustatory persistence. CP obtained the best score for olfactory intensity, olfactory persistence, gustatory intensity, gustatory persistence and body. Finally, TC had less colour intensity and higher astringency. As expected, the main fragrance notes perceived in all the wines were soft fruits and cherry, with the frequency ranging from 8 to 10 for the former, and from 6 to 10 for the latter (Fig. 1B). As to the other descriptors, AP was characterised by clear notes of clove, violet and plum, TC by notes of clove, black pepper and liquorice, and CP by descriptors of clove, plum, violet, liquorice and black sherry in brandy.

\section{CONCLUSIONS}

The present study represents the first specific investigation of Primitivo wines from Gioia del Colle PDO, and provides suitable information on their characteristics. The results demonstrate a high quality of the phenolic fraction and sensory attributes, although the wine samples derived from grapes with different characteristics and were made by different winemaking technologies. All wines were characterised by a high alcohol content, good phenolic structure and richness in proanthocyanidins, known as "good tannins" for their sensory and health properties. As regards the anthocyanin profile, the samples presented a prevalence of non-acylated forms, with malvidin-3-monoglucoside being predominant. Esters were the most numerous compounds in the volatile fraction, and almost all of them had a concentration above the odour threshold, suggesting a strong impact on aroma perception. All the wines were highly appreciated for their sensory characteristics, and only slight differences were observed in olfactory and gustatory persistence. Finally, the odour attributes soft fruit, cherry and cloves were found to be common characteristics of Primitivo wines.

\section{LITERATURE CITED}

Antonacci, D. 2004. In: Adda, M. (ed). I vitigni dei vini di Puglia. Edizioni Pugliesi, Martina Franca 2, 288-290.

Baiano, A., Terracone, C., Gambacorta, G. \& La Notte, E., 2009. Phenolic content and antioxidant activity of Primitivo wine: Comparison among winemaking technologies. J. Food Sci. 74, 259-267.

Baumes, R., 2000 ( $2^{\text {nd }}$ ed). Los constituyentes volatiles de la etapa fermentativa. In: Flanzy, C. (ed). Enología: Fundamentos científicos y tecnológicos (pp. 147-158). AMV. Almansa, Madrid.

Bianchi, F., Careri, M., Mangia, A. \& Musci, M., 2007. Retention indices in the analysis of food aroma volatile compounds in temperature-programmed gas chromatography: Database creation and evaluation of precision and robustness. J. Sep. Sci. 30, 563-572.

Bononi, M., Tateo, F. \& Liuzzi, V., 2005. Application of stir bar sorptive extraction (SBSE) to evaluate the volatile compounds' profile of Primitivo wine. J. Food Technol. 3, 319-325.

Burns, J., Mullen, W., Landrault, N., Teissedre, P.L., Lean, M.E.J. \& Crozier, A., 2002. Variations in the profile and content of anthocyanins in wines made from Cabernet Sauvignon and hybrid grapes. J. Agr. Food Chem. 50, 4096-4102. 
Buttery, R.G., Turnbaugh, J.G. \& Ling, L.-C., 1988. Contribution of volatiles to rice aroma. J. Agr. Food Chem. 36, 1006-1009.

Canuti, V., Conversano, M., Calzi, M.L., Heyman, H., Matthews, M.A. \& Eleber, S.E., 2009. Headspace solid-phase microextraction-gas chromatography-mass spectrometry for profiling free volatile compounds in Cabernet Sauvignon grapes and wines. J. Chromatogr. A 1216, 3012-3022.

Capone, S., Tufariello, M., Francioso, L., Montagna, G., Casino, F., Leone, A. \& Siciliano, P., 2013. Aroma analysis by GC/MS and electronic nose dedicated to Negroamaro and Primitivo typical Italian Apulian wines. Sensor. Actuat. B-Chem. 179, 259-269.

Castellarin, S., Matthews, M., Di Gaspero, G. \& Gambetta, G., 2007. Water deficits accelerate ripening and induce changes in gene expression regulating flavonoid biosynthesis in grape berries. Planta 227, 101-112.

Coletta, A., Trani, A., Faccia, M., Punzi, R., Dipalmo, T., Crupi, P., Antonacci, D. \& Gambacorta, G., 2013. Influence of viticultural practices and winemaking technologies on phenolic composition and sensory characteristics of Negroamaro red wines. Int. J. Food Sci. Technol. 48, 2215-2227.

Di Stefano, R. \& Cravero, M.C., 2001. Methods for grape phenolic compound study. Riv. Vitic. Enol. 2, 37-45.

EEC, 1990. European Communities. Commission Regulation No 2676/90 on "Community Analysis Methods to Use in Wine Sector". Official Journal of European Communities No. L272/3.10.90.

Etiévant, P.X., 1991. Wine. In: Maarse, H. (ed). Volatile compounds of food and beverages. Dekker, New York. pp. $483-586$.

Evans, C.D., Moser, H.A. \& List, G.R., 1971. Odor and flavor responses to additives in edible oils. J. Am. Oil Chem. Soc. 48, 495-498.

Fazzalari, F.A., 1978. Compilation of odor and taste threshold data. ASTM Data Series DS 48A.

Fernández-Pachón, M.S., Villaño, D., García-Parilla, M.C. \& Troncoso, A.M., 2004. Antioxidant activity of wines and relation with their polyphenolic composition. Anal. Chim. Acta 513, 113-118.

Ferreira, V., Lòpez, R. \& Cacho, J.F., 2000. Quantitative determination of the odorants of young red wines from different grape varieties. J. Sci. Food Agr. 80, 1659-1667.

Fragasso, M., Antonacci, D., Pati, S., Tufariello, M., Baiano, A., Forleo, L.R., Caputo, A.R. \& La Notte, E., 2012. Influence of training system on volatile and sensory profile of Primitivo grapes and wines. Am. J. Enol. Viticult. 63, 477-486.

Fresco, P., Borges, F., Diniz, C. \& Marques, M.P., 2006. New insights on the anticancer properties of dietary polyphenols. Med. Res. Rev. 26, 747-766.

Gambacorta, G., Antonacci, D., La Gatta, M., Faccia, M., La Gatta, B., Pati, S., Coletta, A. \& La Notte, E., 2011a. Phenolic composition of Aglianico and Nero di Troia grapes and wines as affected by cover cropping and irrigation. Ital. J. Food Sci. 23, 381-394.

Gambacorta, G., Antonacci, D., Pati, S., La Gatta, M., Faccia, M., Coletta, A. \& La Notte, E., 2011b. Influence of winemaking technologies on phenolic composition of Italian red wines. Eur. Food Res. Technol. 233, 1057-1066.

Gil Diaz, M., Cabellos Caballero, J.M. \& Arroyo Casado, T., 2005. Caracterizacion varietal de mostos de la denominacion de origen Vinos de Madrid. Viticultura Enologia Profesional 96, 9-18.

Glories, Y., 1984. La couleur des vins rouges. Les equilibres des anthocyanes et des tannins. Partie I. Conn. Vigne Vin 18, 195-217.

Guth, H., 1997. Quantification and sensory studies of character impact odorants of different white wines varieties. J. Agr. Food Chem. 45, 30273032 .
Kosir, I.J., Lapornik, B., Andrensek, S., Wondra, A.G., Vrhovsek, U., \& Kidri, J., 2004. Identification of anthocyanins in wines by liquid chromatography, liquid chromatography-mass spectrometry and nuclear magnetic resonance. Anal. Chim. Acta 513, 277-282.

Kotseridis, Y. \& Baumes, R., 2000. Identification of impact odorants in Bordeaux red grape juice, in the commercial yeast used for its fermentation and in the produced. J. Agr. Food Chem. 48, 400-406.

Li, H., Wang, X., Li, Y., Li, P. \& Wang, H., 2009. Polyphenolic compounds and antioxidant properties of selected China wines. Food Chem. 112, 454460 .

Ojeda, H., Andare, C., Traeva, E., Carbonneau, A. \& Deloire, A., 2002. Influence of pre- and postveraison water deficit on synthesis and concentration of skin phenolic compounds during berry growth of Vitis vinifera cv. Shiraz. Am. J. Enol. Vitic. 53, 261-267.

Ortega-Regules, A., Ros-García, J.M., Bautista-Ortín, A.B., López-Roca, J.M. \& Gómez-Plaza, E., 2008. Changes in skin cell wall composition during the maturation of four premium wine grape varieties. J. Sci. Food Agric. 88, 420-428.

Otteneder, H., Marx, R. \& Zimmer, M., 2008. Analysis of the anthocyanin composition of Cabernet Sauvignon and Portugieser wines provides an objective assessment of the grape varieties. Aust. J. Grape Wine Res. 10, $3-7$.

Pisarnitskii, A.F., 2001. Formation of wine aroma: Tones and imperfections caused by minor components. Appl. Biochem. Microb. 37, 552-560.

Polášková, P., Herszage, J. \& Ebeler, S.E., 2008. Wine flavor: Chemistry in a glass. Chem. Soc. Rev. 37, 2478-2489.

Rapp, A., 1990. Natural flavours of wine: Correlation between instrumental analysis and sensory perception. J. Anal. Chem. 337, 777-785.

Re, R., Pellegrini, N., Pannala, A., Yang, M. \& Rice-Evans, C., 1999. Antioxidant activity applying an improved ABTS radical cation decolorization assay. Free Radical Bio. Med. 26, 1231-1237.

Revilla, E. \& Ryan, L.M., 2000. Analysis of several phenolic compounds with potential antioxidant properties in grape extracts and wines by highperformance liquid chromatography-photodiode array detection without sample preparation. J. Chromat. A. 881, 461-469.

Ribéreau-Gayon, P., Glories, Y., Maujean, A. \& Dubourdieu, D., 2006 (2 $2^{\text {nd }}$ ed). Handbook of Enology. Vol 2. The chemistry of wine stabilization and treatments. John Wiley \& Sons, Chichester, England.

Rocha, S.M., Rodrigues, F., Coutinho, P., Delgadillo, I. \& Coimbra, M.A., 2004. Volatile composition of Baga red wine. Assessment of the identification of the would-be impact odourants. Anal. Chim. Acta 513, 257-262.

Romero-Cascales, I., Ortega-Regules, A., López-Roca, J.M., FernándezFernández, J.I. \& Gómez-Plaza, E., 2005. Differences in anthocyanin extractability from grapes to wines according to variety. Am. J. Enol. Vitic. $56,212-219$

Sagratini, G., Maggi, F., Caprioli, G., Cristalli, G., Ricciutelli, M., Torregiani, E. \& Vittori, S., 2012. Comparative study of aroma profile and phenolic content of Montepulciano monovarietal red wines from the Marches and Abruzzo regions of Italy using HS-SPME-GC-MS and HPLCMS. Food Chem. 132, 1592-1599.

Silva Ferreira, A.C., 1998. Caractérisation du vieillissement du vin de Porto. Approche chimique et statistique. Rôle aromatique du sotolon. Ph.D. Thesis (593), Université Victor Segalen Bordeaux 2, France.

Soleas, G.J., Grass, L., Josephy, P.D., Goldberg, D.M. \& Diamandis, E.P., 2006. A comparison of the anticarcinogenic properties of four red wine polyphenols. Clin. Biochem. 39, 492-497. 
Summo, C., Trani, A., Faccia, M., Caponio, F. \& Gambacorta, G. 2016. Volatile and acceptability of liqueurs from kumquat and grapefruit. Ital. J. Food Sci. 28, 258-270.

Suriano, S., Alba, V., Tarricone, L. \& Di Gennaro, D., 2015. Maceration with stems contact fermentation: Effect on proanthocyanidins compounds and color in Primitivo red wines. Food Chem. 177, 382-389.

Swiegers, J.H. \& Pretorius, I.S., 2005. Yeast modulation of wine flavour. Adv. Appl. Microbiol. 57, 131-175.
Takeoka, G.R., Flath, R.A., Mon, T.R., Teranishi, R. \& Guentert, M., 1990. Volatile constituents of apricot (Prunus armeniaca). J. Agr. Food Chem. $38,471-477$.

Zea, L., Moyano, L., Moreno, J., Cortes, B. \& Medina, M., 2001. Discrimination of the aroma fraction of sherry wines obtained by oxidative and biological ageing. Food Chem. 75, 79-84. 